Mathematical Programming 10 (1976) 140.

North-Holland Publishing Company

\title{
NOTICE
}

\section{TO MEMBERS OF THE M.P.S.: DUES}

You will be confronted shortly with the dues notice for 1976. As your membership dues have changed again, I would like to give you more information about the way in which they are settled, and about the main and unavoidable causes of change.

The main component of these dues is the price charged by the Publisher for the Journal. The steady increase of publishing costs is caused by inflation in the Netherlands economy of some $10 \%$, which is not alarmingly high in comparison with the international situation.

The other smaller component of the membership dues is the costs of the Secretariat at the International Statistical Institute (I.S.I.) at Voorburg/the Hague, which has its siege in the Dutch Central Bureau of Statistics (C.B.S.). These Secretariat costs are modified in accordance with the official C.B.S. index, according to the M.P.S. contract with I.S.I.; this index again reflects the inflatory trend of Dutch economy.

Taking account of these effects, the dues are settled every year in Dutch currency primarily, being the currency of both components mentioned above.

To settle the dues figures for other currencies ( $£$, French and Swiss francs, DM, \$), the exchange rates in the Dutch National Bank are used as reported officially at the end of the week preceding the printing of the dues notices. The figures obtained are rounded to sensible currency units.

Now, obviously apart from the Dutch inflation effects mentioned above, further changes in the dues occur from year to year as the result of the international monetary developments. 